\title{
As relações contratuais das indústrias criativas: o caso dos quadrinhos no Ceará
}

\author{
The contractual relations of the creative industries: the case of the comics sector in Ceará
}

\author{
Paulo César de Sousa Batista ${ }^{1}$ \\ Thiago Alves Paiva ${ }^{2}$ \\ Roberto Rodrigues Ramos ${ }^{3}$ \\ Priscilla Correa da Hora Almeida ${ }^{4}$ \\ Leonel Gois Lima Oliveira ${ }^{5}$
}

\section{Resumo}

O segmento dos quadrinhos, inserido no contexto das indústrias criativas, tem assumido relevância econômica e cultural. Sendo assim, esta pesquisa tem como objetivo principal analisar fatores importantes do processo de contratação dos profissionais dessa área. O foco será na relação contratual entre os dois principais protagonistas das indústrias criativas, o artista e o agente, sendo que as análises serão baseadas na percepção dos artistas a respeito, principalmente, dos custos de transação, direitos autorais, assimetria de informações e agentes de mercado. O estudo de caráter descritivo e exploratório fez uso de métodos qualitativos também nas entrevistas realizadas no trabalho empírico. Os respondentes fazem parte da indústria criativa cearense e atuam no setor de quadrinhos. Os principais resultados encontrados pela análise de conteúdo das entrevistas diz respeito, basicamente, a falta de profissionalismo ainda existente no setor de quadrinhos da indústria criativa cearense. Há ainda, conforme indícios desta pesquisa, falta de visão mercadológica e de mentalidade profissional dos artistas, ausência de agentes especializados para interferir comercialmente, e a ausência de proteção aos direitos autorais e conexos. Acredita-se que os resultados aqui disponibilizados podem gerar informações relevantes para a melhor compreensão do mercado tido como objeto de estudo, e com isso colaborar na profissionalização deste importante segmento cultural para a atual economia.

Palavras-chave: indústrias criativas; propriedade intelectual; história em quadrinhos.

Artigo submetido em agosto de 2009 e aceito para publicação em novembro de 2009.

1 Ph.D em Economia pela University of Illinois, USA; Professor adjunto da Universidade Estadual do Ceará (UECE). Endereço: CMAAd/UECE - Curso de Mestrado Acadêmico em Administração, Rua Pereira Filgueiras, 1931, Sala 208, Centro, CEP 60160-150, Fortaleza, CE, Brasil. E-mail: batista.pcs@gmail.com

2 Bacharel em Administração pela UECE; Instituto a Vez do Mestre. Endereço: Avenida Alberto Nepomuceno, 02, Centro, CEP 60055000, Fortaleza, CE, Brasil. E-mail: talvesp@gmail.com

3 Mestre em Administração pela UECE; Professor Assistente da Universidade Federal do Ceará (UFC) - Campus Juazeiro do Norte. Endereço: Av. Tenente Raimundo Rocha, s/n, Cidade Universitária, CEP 63040-360, Juazeiro do Norte, CE, Brasil. E-mail: robertoramos1977@gmail.com

4 Mestre em Administração pela UECE. Endereço: Avenida Paranjana, 1700, Campus do Itaperi, CEP 60740-000, Fortaleza, CE, Brasil. E-mail: prishora@yahoo.com.br

${ }^{5}$ Doutorando em Administração pela Fundação Getúlio Vargas/EBAPE; Mestre em Administração pela UECE. Endereço: FGV/EBAPE - Escola Brasileira de Administração Pública e de Empresas, Praia de Botafogo, 190 - 4ํ e 5ํo andares, CEP 22253-900, Rio de Janeiro, RJ, Brasil. E-mail: leonelgois@gmail.com 


\begin{abstract}
The comics segment, in the context of creative industries, has achieved economic and cultural importance. Thus, this study aims to examine the important factors in the recruitment process of professionals in this areas. The focus will be on contractual relationship between the two main protagonists of the creative industries, the artist and the agent, and the analysis will be based on the perception of the artists with the area. primarily concerning transaction costs, copyright, asymmetry of information and agents of the market. The study is descriptive and exploratory nature, using the qualitative methods also the interviews in empirical work. The respondents are part of the creative industry sector in Ceará and work with comics. The main results found by the content analysis of the interviews is concerned, basically, with the lack of professionalism even in the comics sector of the creative industry of Ceará. There is, as evidence of this research, a lack of vision and marketing mindset of professional artists, a shortage of specialist agents to interfere commercially, and the lack of protection of copyright and related rights. It is believed that the results displayed here can generate information for better understanding of the market as its object of study, and to assist in the professionalism of this important segment of the current cultural economy.
\end{abstract}

Keywords: creative industries; intellectual property; comics.

\title{
Introdução
}

O segmento das indústrias criativas cresce ano após ano no mundo. Segundo dados do relatório Creative Economy Report da Organização das Nações Unidas (UN, 2008), no período compreendido entres os anos 2000 e 2005, a oferta de produtos e serviços desse setor econômico cresceu a uma taxa de $8,7 \%$ ao ano, desempenho superior ao da economia mundial, a qual nunca ultrapassou $5 \%$ ao ano, entre os anos 2000 e 2008 (IMF, 2008). Os negócios internacionais do setor também se expandiram favoravelmente, quase que duplicando, ao passarem de 227,5 bilhões de dólares em 1996 para 424,4 bilhões de dólares em 2005 (UN, 2008).

A definição de Indústrias Criativas é dada por Hanson e Gomes (2007, p. 1), com base no documento Creative Industries Task Force Mapping Document, como sendo "as atividades que têm suas origens na criatividade individual, habilidade e talento e que têm o potencial para a criação de riquezas e emprego por meio da geração e da exploração da propriedade intelectual". As indústrias criativas são compostas por diversos segmentos, podendo destacar, por exemplo, o cinema, o teatro e as histórias em quadrinhos (HQs).

As HQs, objeto desta pesquisa, são um meio de comunicação que combina imagens estáticas com elementos textuais, buscando construir uma narrativa ou transmitir informações. Servem como suporte para diversas ideias e mensagens, com finalidades artísticas, educativas e políticas (CIRNE, 1974; ANSELMO, 1975; MOYA, 1977; EISNER, 1985; MCCLOUD, 1995; CAVEDON; LENGLER, 2005). O número de publicações direcionadas para segmentos de público adulto, por exemplo, cresceu consideravelmente nas últimas duas décadas, embora a publicação de títulos para o público infantil e adolescente ainda seja substancial (VERGUEIRO, 2007).

Entretanto, pesquisas que abordam o aspecto econômico desse setor são raras. Um estudo da produção científica na USP, do período de 1972 a 2005, revelou que nenhum trabalho sobre o impacto econômico desta atividade foi publicado, embora se verifique uma forte tendência dos quadrinhos em direção à diversificação de públicos e à diferenciação de produtos (VERGUEIRO; SANTOS, 2006; VERGUEIRO, 2007). 0 trabalho desenvolvido por Batista et al. (2008) destaca-se pela demonstração da 
cadeia produtiva da indústria dos quadrinhos no Ceará. Deste modo, verifica-se que gradativamente o interesse pela economia do segmento é retomado.

Assim como o crescimento desse mercado, os estudos nesse campo ainda são recentes e muitas pesquisas ainda se concentram na delimitação do campo conceitual (CAVES, 2003). Alguns autores como Caves (2003) e Hartley (2005) têm estudado as peculiaridades da indústria criativa em relação a outras indústrias e discutido como as características inerentes ao setor criativo dificultam a sua padronização e consequente comercialização.

Entretanto as variáveis envolvidas nas relações contratuais das indústrias criativas como os custos transacionais, a assimetria de informações e existência de informações incompletas e os custos irrecuperáveis (sunk costs) são ainda pouco explorados, havendo um vácuo de informação a respeito dos contratos, pela falta de uma análise mais focada em como esses contratos são redigidos na prática e quais são seus termos (CAVES, 2003).

Em vista dessa lacuna na produção científica e considerando a importância econômica e cultural que o segmento de quadrinhos tem assumido, objetiva-se, neste artigo, aprofundar o debate a respeito dos aspectos envolvidos no processo de contratação dos artistas de histórias em quadrinhos e pesquisar como se dão as relações contratuais nesse setor. Desta forma, o presente trabalho busca aprofundar o trabalho desenvolvido por Batista, Oliveira e Andrade (2010) que apresentou como algumas destas questões de propriedade intelectual são tratadas pelos quadrinistas cearenses.

O campo empírico pesquisado é a indústria de história em quadrinhos, por meio dos desenhistas e figurinistas cearenses atuantes no setor, ou seja, a percepção do artista neste contexto. Através de uma pesquisa qualitativa, na qual foram entrevistados 8 (oito) atores representativos no segmento regional; sendo 2 (dois) desenhistas freelance, 3 (três) fanzinistas, 1 (um) quadrinista exportador de desenhos e 2 (dois) figurinistas e quadrinistas de jornais de grande circulação.

Após esta introdução, o artigo traz uma análise sobre a teoria dos contratos, passando pela teoria dos custos de transação, pelas informações assimétricas ou incompletas (nobody knows), chegando ao conceito de art for art sakes (arte pela arte). São abordados também pontos inerentes à propriedade intelectual, aos direitos autorais e peculiaridades das indústrias criativas, em especial sobre as HQs. Em uma seção seguinte é apresentada a metodologia utilizada nesta pesquisa. Posteriormente, tem-se a análise e discussão dos resultados, onde se buscou responder indagações sobre como se dão, na prática, as relações contratuais no setor de histórias em quadrinhos cearenses, e quais são as principais nuances envolvidas. Por fim, estão feitas as considerações finais, onde se discute a relevância instrumental e conceitual do artigo, se reconhece suas limitações e se oferece direcionamentos para futuros estudos.

\section{Teoria dos Custos de Transação e Teoria da Agência}

As relações contratuais são acompanhadas de algumas variáveis que interferem direta ou indiretamente sobre o que está sendo acordado, discutido ou negociado. Essas variáveis fazem parte das relações comerciais e geram impactos, muitas vezes financeiros, no resultado final do negócio. Coase (1937) afirmou que todas as transações entre os agentes econômicos estavam recheadas de custos que, muitas vezes, passavam despercebidos. Tais custos, normalmente, encontravam-se atrelados à obtenção de informações ou à realização da negociação e concretização do acordo entre as partes (AZEVEDO, 2006). 
A utilização dos mecanismos de preços acarreta custos, tanto para descobrir os preços relevantes, quanto para firmar negociações e formular contratos que acompanham cada transação realizada e a não superação dos custos de transação pelas empresas normalmente se dá por três razões: primeiro, pelo fato dos retornos diminuírem nas atividades de administração com o aumento de transações pela organização; segundo, por que quanto mais transações a cargo dos gestores, maior é a tendência de erros e; terceiro, pela relação entre o aumento de preço dos fatores de produção e o próprio crescimento da firma (COASE, 1937).

Com base na "teoria coaseana", Oliver Williamson iniciou seus estudos sobre a economia dos custos de transação (ECT) por perceber que os institutos econômicos que fazem parte do capitalismo não estavam tendo a devida atenção (FAGUNDES, 1997; PESSALI, 1998). Atestando a complexidade destes institutos, ele entendia que só se podia fazer uma avaliação completa se estes custos fossem considerados, o que traria vantagem a qualquer análise de um problema.

O processo de contratação tem na sua essência os custos de transação ex ante e ex post. Quando ocorrem antes, normalmente referem-se a uma negociação, à elaboração do instrumento contratual e a maneiras de salvaguardar um acordo. Não necessariamente todos os aspectos serão abordados em um contrato, por haver a possibilidade de surgimento de contingências futuras, segundo Williamson (1985), que ainda vê esse instrumento, como forma mais óbvia e comum para salvaguardar a ideia de propriedade comum.

Os custos de transação ex post existem após a concretização do negócio e, em regra, são consequência de novas situações até então estranhas. Tais custos podem aparecer de quatro formas distintas: (a) por má adaptação contratual; (b) por realinhamento; (c) associados à instalação e ao funcionamento da estrutura governamental; e (d) necessários para se garantir o comprometimento das partes, visando assegurar a inexistência de atitudes oportunistas (WILLIAMSON, 1985).

A pesquisa empírica nas questões sobre custos de transação quase nunca tenta medir esses custos diretamente. Em vez disso, a questão é saber se as relações organizacionais (práticas contratuais; estruturas de governança) alinham-se com os atributos das transações como previstos pelos custos de transação. Podese perceber nesta classificação ex ante e ex post dois pressupostos inerentes à Teoria dos Custos de Transação (TCT): os indivíduos são oportunistas e têm a racionalidade limitada (WILLIAMSON, 1985; FAGUNDES, 1997; PESSALI, 1998; AZEVEDO, 2006).

Azevedo (2006) traz três dimensões principais dos custos de transação: (i) frequência, medida da recorrência com que uma transação se efetiva; (ii) incerteza, ampliação das lacunas que um contrato não pode cobrir; (iii) especificidade dos ativos, se o retorno associado a eles depender da continuidade de uma transação específica. Estas dimensões conduzem às seguintes conclusões: (a) quando a frequência é elevada tende-se a reduzir as atitudes oportunistas; (b) em ambiente muito incerto, a possibilidade de renegociação aumenta e consequentemente a possibilidade de uma ação oportunista; (c) quanto maior a especificidade do ativo, maior a perda relacionada a uma ação oportunista e maiores os custos de transação.

Nesta perspectiva dos custos de transação, as particularidades de cada mercado precisam ser observadas, pois existem falhas que tendem a influenciar diretamente as negociações. Uma das principais falhas de mercado assinaladas na literatura é a assimetria de informações (SANTANA, 2004). Esta se caracteriza por se tratar de informações que o comprador ou o vendedor possui, mas que a outra parte não tem acesso ou não há a possibilidade de verificação. O segmento dominado por esta falha é chamado de "mercado de limões", nele as pessoas desconsideram todas as alegações não verificáveis feitas pela outra parte, que acabam negociando bens ou serviços a preços inferiores ao de oferta (MCGUIGAN; MOYER; HARRIS, 2004).

No caso da indústria criativa, o comum é ter que lidar com a ignorância simétrica, dos produtores em relação ao gosto dos consumidores e destes em relação ao produto em si. Essas informações só são obtidas após o 
produto ter sido finalizado e colocado diante do consumidor, que algumas vezes precisa primeiro consumi-lo para só depois se manifestar positivamente ou não (CAVES, 2003).

Além da assimetria de informações, as partes envolvidas em uma negociação podem enfrentar a existência de informações incompletas ou até mesmo desconhecidas. Estas se caracterizam pela incerteza e generalidade, ou seja, não há divergência de informações entre as partes (MCGUIGAN; MOYER; HARRIS, 2004). Especificamente em termos de indústria criativa, Caves (2003) nomeia essa incerteza de informações ou desconhecimento de informações como nobody knows (ninguém sabe). Na prática, ninguém sabe o que irá acontecer, qual será a receptividade do público e se a produção fará sucesso comercial ou não. Caves (2003) afirma que é importante a aplicação da teoria dos contratos nas indústrias criativas, pois assimetria de informações e informações desconhecidas, presente em tal setor, são preocupações chaves nas negociações contratuais.

No percurso até que sua obra seja produto no mercado, várias etapas são percorridas pelo artista. Durante o processo surge a figura dos Humdrum inputs, que na indústria criativa "são os incentivos econômicos normais que ajudam aos trabalhos artísticos a chegarem ao conhecimento dos consumidores" (CAVES, 2003, p.73). Podem ainda ser vistos como pessoas ou organizações, tais como as galerias de arte, os editores, as gravadoras, que promovem o trabalho dos artistas em troca de ganhos econômicos. Muitas vezes são esses agentes que viabilizam até mesmo a produção de muitos artistas, sendo de grande importância para a produção e disseminação dos produtos da indústria criativa.

Não obstante os diversos aspectos destacados, o artista ainda pode se ver em meio a um dilema de conotação filosófica, o porquê produzir. Um dos fatores que ganha mais destaque neste aspecto é a chamado por Caves (2003) de arte pela arte (art for art sakes). O artista que pensa assim pode aceitar uma baixa remuneração, normalmente no mesmo nível que receberia para fazer trabalhos comuns, para fazer sua arte. Na visão dos artistas, isso já seria um grande avanço, pois estaria ganhando a mesma quantia para fazer uma atividade que lhe dá prazer, ao invés de um trabalho qualquer.

\section{Propriedade Intelectual, Direitos Autorais e Conexos}

Dado o avanço dos meios pelos quais é possível produzir, distribuir e mesmo disseminar produtos da indústria cultural, tem-se tornado comum a cópia de softwares, as fotocópias de livros, o download de músicas na Internet, entre outras questões que tem estimulado a discussão quanto à propriedade intelectual e a defesa dos direitos dos atores envolvidos nas relações comerciais desse tipo de atividade. Segundo a World Intellectual Property Organization (WIPO, 2004), o conceito de propriedade intelectual estabelece-se por meio dos direitos relativos a:

Obras literárias, artísticas e cientificas; interpretações dos artistas interpretes e execuções dos artistas executantes, fonogramas e emissões de radiodifusão; invenções em todos os domínios da atividade humana; descobertas científicas; desenhos e modelos industriais; marcas industriais, comerciais; proteção contra a concorrência desleal e todos os outros direitos inerentes à atividade intelectual nos domínios industrial, científico, literário e artístico.

Definição similar pode ser vista em Pereira (2003, p. 4), quando diz que: 
[...] a propriedade intelectual está relacionada com as criações da mente, tais como as invenções, as obras literárias e artísticas, os símbolos, os nomes, as imagens e as técnicas e modelos utilizados no comércio.

O referido autor ainda divide a Propriedade Intelectual em duas categorias: a industrial, a qual inclui as invenções, patentes, marcas, técnicas e modelos industriais e indicações geográficas de origem; e o direito de autor, que abrange as obras literárias e artísticas, tais como os filmes, pinturas, fotografias e esculturas, e os desenhos arquitetônicos entre outros. Apenas esta última classificação apresenta-se como relevante para este estudo que foca na pessoa do artista.

Os direitos do autor são divididos em morais e patrimoniais. Os morais são aqueles relativos à tutela da expressão, que é o direito de fazer pública a obra, e o de resguardo de sua integridade. São direitos morais: direito de divulgação, direito de nominação, direito de retirar a obra de circulação, direito de promover alterações, dentre outros. Já os direitos patrimoniais são os direitos de propriedade, aqueles relativos à utilização, publicação ou reprodução da obra. Os direitos patrimoniais regulam as relações jurídicas da utilização econômica as obras intelectuais (BRASIL, 1998; MARTINS FILHO, 1998; HANSON; GOMES, 2007). O Quadro 1 apresenta uma descrição dos direitos autorais.

\section{Quadro 1}

\section{Direitos do Autor}

\begin{tabular}{|l|l|}
\hline $\begin{array}{l}\text { Direitos de Reprodução } \\
\text { (copyrights) }\end{array}$ & $\begin{array}{l}\text { edição de livros, fotocópias, gravação de fitas e reprodução dessas } \\
\text { gravações, armazenagem de obras em memórias de computador e } \\
\text { reprodução de programas em disquetes, CD-Rom, etc. }\end{array}$ \\
\hline $\begin{array}{l}\text { Direito de Interpretação e de } \\
\text { Execução. }\end{array}$ & $\begin{array}{l}\text { por exemplo, o direito de interpretar uma canção e o direito de } \\
\text { comunicar a obra ao público e proceder à sua radiodifusão. A Lei } \\
\text { considera "direitos autorais" os direitos de autor e os que lhes são } \\
\text { conexos. }\end{array}$ \\
\hline
\end{tabular}

Fonte: Adaptado de Hanson e Gomes (2007, p. 7).

Os direitos autorais de uma obra se estendem por toda a vida do autor e por mais um prazo convencionado, o qual é determinado pela legislação de cada país. Terminado este período, a obra entra em domínio público podendo ser usada sem a necessidade de prévia autorização do autor ou detentor dos direitos. A Convenção de Berna, mais antiga convenção sobre direito autoral, firmada em 1886, determina como prazo mínimo o período de 50 anos, os quais são calculados a partir do final do ano do falecimento do autor. No entanto a tendência mundial tem sido prolongar esta proteção para 70 anos.

Países como o Brasil, os Estados Unidos e os da União Européia têm seguido essa tendência. A lei brasileira calcula este prazo após a morte do autor contando a partir do primeiro dia de janeiro do ano subsequente ao seu falecimento, dependendo de autorização expressa dos herdeiros ou sucessores para a utilização ou divulgação (WIPO, 1979; BRASIL, 1998; MARTINS FILHO, 1998; HANSON; GOMES, 2007). A violação do direito autoral é considerada crime contra a propriedade Intelectual, de acordo com o Art. 184 do Código Penal Brasileiro, estando aquele que infligi-lo sujeito a pena de detenção de três meses a um ano ou ainda ao pagamento de multa. 


\section{A Indústria das Histórias em Quadrinhos (HQs)}

As histórias em quadrinhos (HQs) podem ser definidas como uma forma de expressão artística constituída por dois tipos de linguagem: a gráfica (imagem) e a verbal (texto). Os quadrinhos apresentam aspectos essencialmente modernos: reprodutibilidade, divulgação e velocidade de consumo. Elementos fundamentais são facilmente identificados nas HQs: o quadrinho em si, o balão, as onomatopéias e o ritmo visual (estruturação dinâmica, corte de quadros, gestualidade etc.) (CIRNE, 1974; MOYA, 1977; EISNER, 1985; MCCLOUD, 1995; CAVEDON; LENGLER, 2005; BATISTA et al., 2008).

Verifica-se uma distinção na maneira de leitura das histórias em quadrinhos. No mundo ocidental é realizada da esquerda para a direita e de cima para baixo, enquanto nos mangás (quadrinhos japoneses) o processo é invertido (CAVEDON; LENGLER, 2005; GRAVETT, 2006; PATATI; BRAGA, 2006; BATISTA et al., 2008).

A propriedade intelectual nos quadrinhos apresenta-se como instrumento de garantia para os responsáveis pelo processo artístico gráfico e verbal e, inclusive, para os responsáveis pela reprodução e distribuição. Desta forma, a indústria dos quadrinhos se utiliza de duas manifestações de proteção da propriedade intelectual: o direito autoral e os direitos conexos. A criação e o desenvolvimento de um personagem ou o roteiro de uma história são exemplos de propriedade autoral. Enquanto os assuntos relacionados à reprodução e exibição se referem aos direitos conexos (BATISTA; OLIVEIRA, ANDRADE, 2010).

Os syndicates nos EUA merecem destaque na história do processo de produção de quadrinhos e de sua distribuição pelo mundo. Eles foram responsáveis pela grande difusão mundial dos quadrinhos a um baixo custo devido a elevada tiragem das obras produzidas. Segundo Furlan (1985, p. 29), a denominação "syndicate, nos moldes norte-americanos, não encontra similar em nosso contexto". Não se trata de um sindicato e ultrapassa as atribuições de uma associação. Podemos tratá-los como agência especializada em fornecer matérias variadas, particularmente de entretenimento. Os syndicates possuíam os direitos de venda e distribuição sobre os trabalhos dos desenhistas, embora lhes permitissem não se submeterem as determinações dos jornais, garantindo certa autonomia. Os desenhistas deviam seguir as políticas dos syndicates na elaboração de seus trabalhos, impostas por um rigoroso código de ética que nivelava o conteúdo a fim de colocar os desenhos em qualquer sociedade, inclusive as mais moralistas. Henfil, desenhista brasileiro, produziu obras para os syndicates, mas seus trabalhos não duraram dois meses, embora tenham sido distribuídos para cerca de 10 jornais americanos. Vários leitores enviaram correspondências reclamando contra o humor aguçado de Henfil e os jornais cancelaram os contratos (HENFIL, 1983; FURLAN, 1985; LACHTERMACHER; MIGUEL, 1985; LUYTEN, 1985; MAGALHÃES, 2005).

O caso da participação do Henfil no esquema dos syndicates merece uma atenção especial por retratar bem e de maneira detalhada um processo de formalização contratual. O Universal Press Syndicate (UPS) queria assinar um contrato padrão com Henfil contendo as seguintes cláusulas: validade do contrato por 22 anos; utilização dos personagens em peças publicitárias; utilização dos personagens com produtos industriais (merchandising); venda dos quadrinhos para todos os países que o UPS tivesse ou fizesse negociações. Estas exigências apresentaram-se como absurdas para Henfil. Apesar de fortes resistências do UPS, Henfil assinou o contrato com as seguintes modificações: 8 anos de contrato com opção de prorrogação por mais 7 anos; vetou o merchandising e a publicidade dos personagens para as empresas multinacionais; a distribuição dos quadrinhos para o Brasil foi retirada do contrato (Henfil já possuía contrato de publicação no país). No final, "[...], assinamos o contrato. Não teve de registrar na junta comercial. A palavra e a assinatura valem" (HENFIL, 1983, p. 207).

Não é somente o desenho que recebe proteção. Moreira (2000) ressalta que recebem proteção tanto as obras em si, como os títulos, os personagens, os nomes, as expressões e elementos outros que as integram, pois o 
Direito Autoral protege a forma externa e a interna da criação. Os quadrinistas criadores possuem o direito de autor de seus desenhos. Segundo Patati e Braga (2006, p. 20), "as editoras não compram a posse dos desenhos, mas os direitos de reprodução desses desenhos". Desta forma, os criadores podem se beneficiar e prolongar a vida e os contextos de seus personagens ilimitadamente. Neste mercado, a relação entre os quadrinistas e os editores é de intensa confiança mútua. Os editores participam do processo de criação do personagem identificando alguma oportunidade no mercado para consolidar a existência desta novidade (GRAVETT, 2006).

Destaca-se, também, o intercâmbio dos quadrinhos com outros formatos de mídias, principalmente as audiovisuais (cinema, TV, internet). O meio digital surge como um fator de redução de custos, de maior durabilidade e de elevação da amplitude dos mercados, embora em alguns casos os quadrinhos tenham perdido um pouco o seu poder de atratividade do público. (BATISTA et al., 2008). A importância dessa articulação dos quadrinhos com outras mídias pode ser ilustrada pelo exemplo de Patati e Braga (2006, p.221) relativo ao lançamento cinematográfico do Homem-Aranha, que

[...] rendeu 114 milhões de dólares no fim da semana de lançamento, tornando-se a estréia de maior bilheteria de todos os tempos. Seu faturamento bruto foi de mais de 800 milhões de dólares em todo o mundo. [...] Os detentores dos direitos autorais de HQs estão com as orelhas em pé e os olhos bem abertos, atentos para qualquer executivo de cinema que chegue com um contrato milionário na pasta.

Portanto, a relação da propriedade intelectual não se restringe aos aspectos da editoração gráfica. $\mathrm{O}$ envolvimento dos quadrinhos com outras mídias também recebe proteção pelos tratados de propriedade intelectual (BATISTA; OLIVEIRA, ANDRADE, 2010).

O mercado editorial brasileiro nos quadrinhos foi extremamente marcado pelo material americano. Segundo Anselmo (1975, p. 66), as "empresas editoriais publicam histórias importadas. Outras possuem desenhistas brasileiros que criam histórias com personagens consagrados no exterior, sendo o copyright de propriedade da agência de origem do personagem". Portanto, as histórias são criadas no país, mas as produtoras estrangeiras cobram os direitos autorais pela utilização de personagens de sua propriedade. Desta forma, as editoras brasileiras possuem uma equipe de desenhistas, tradutores, roteiristas, redatores etc. para a realização de adaptação dos quadrinhos ao público brasileiro (ANSELMO, 1975).

A produção nacional sempre apresentou dificuldades, salvo algumas exceções. A maior parte dos casos de sucesso aconteceu na lacuna deixada pelo material estrangeiro que não conseguiu atender totalmente a demanda. Em 23 de setembro de 1963, foi aprovado o Decreto-Lei 52.497, visando à nacionalização progressiva dos quadrinhos brasileiros. A lei buscava a formação de uma reserva de mercado. Ela não chegou a ser devidamente implantada, pois houve pressão por parte das editoras, que alegavam a falta de qualidade e quantidade dos quadrinhos nacionais para atender a demanda. Mesmo assim, o público brasileiro conheceu importantes trabalhos nacionais, como, por exemplo, os de Ziraldo e Maurício de Sousa (CIRNE, 1971; LACHTERMACHER; MIGUEL, 1985; GONÇALO JÚNIOR, 2004; PATATI; BRAGA, 2006).

No Brasil, houve inclusive uma experiência nos moldes dos syndicates na década de 80 com a criação da Agência Funarte de Quadrinhos Brasileiros. Embora fosse uma alternativa para a produção brasileira, essa iniciativa não obteve muito êxito devido a restrições estruturais dos órgãos oficiais. As mudanças políticas e a falta de continuidade das políticas públicas contribuíram para o fim da Agência no início da década de 90, no governo Collor de Melo (MAGALHÃES, 2005, p. 72-73). 
Segundo Anselmo (1975, p. 79), "há casos de HQ feitas no país, com heróis estrangeiros, publicadas no Brasil e remetidas ao exterior para publicação em outros idiomas". Verifica-se a produção de histórias desenhadas por brasileiros que exportam seus trabalhos para a publicação no mercado editorial estrangeiro, representando uma globalização do setor de quadrinhos na busca por uma mão-de-obra mais barata com qualidade semelhante ou melhor que a produzida no local da publicação (PATATI; BRAGA, 2006).

\section{Metodologia}

Frente ao entendimento dos autores sobre a insuficiência de estudos sobre os aspectos econômicos das indústrias criativas no Brasil, mais precisamente o segmento de HQs; foi realizada uma pesquisa exploratória para contribuir com a consolidação da compreensão do tema no país. A pesquisa é também descritiva porque faz um levantamento das características da atividade, pesquisando, registrando e analisando o fenômeno, quanto a aspectos previamente selecionados pela análise da literatura.

O propósito do artigo conduziu à escolha da abordagem qualitativa para realizar a investigação, opção justificada pela assertiva de Richardson (1999) de que essa pesquisa é "uma forma adequada para entender a natureza de um fenômeno social". Essa adequação do método ao propósito da investigação é fortalecida pelo conteúdo de simbolismo e subjetividade inerente às indústrias criativas, notadamente de seu segmento baseado na cultura e nas atividades das histórias em quadrinhos. A propósito, é relevante considerar o paralelo feito por Vieira e Zouain (2005, p. 123) entre as artes visuais e a pesquisa qualitativa:

Os artistas dão especial atenção às nuances de qualidades, particularidades, gradações de cores, luzes, sombras, valorizando a estética do trabalho. Os pesquisadores qualitativos dão atenção especial a nuances e qualidades das situações e dos achados, na particularidade de seus casos.

Richardson (1999, p. 80) sugere ainda que uma das situações em que se aplica a pesquisa qualitativa é a do uso das observações qualitativas, "como indicadores de funcionamento de estruturas sociais", como é o caso das indústrias criativas, o que atribui à investigação uma natureza descritiva. A entrevista é a técnica de coleta de dados utilizada na investigação. Ela é, juntamente com a observação, uma técnica apropriada à abordagem qualitativa. Os respondentes da entrevista, em número de 8 (oito), foram selecionados com o uso do critério da bola de neve (snowball), onde os participantes iniciais indicam novos participantes.

No caso específico desse estudo, a entrevista foi orientada por categorias extraídas da literatura sobre aspectos econômicos inerentes a contratos, propriedade intelectual, direitos autorais e conexos, atividades de HQs, estratégia importante para uma análise ordenada das informações colhidas e para conferir credibilidade acadêmica aos resultados. Três foram as categorias selecionados no referencial teórico do trabalho: i) teorias econômicas inerentes a contratos; ii) práticas de comercialização; e iii) direitos autorais e conexos.

Como o foco desta pesquisa é a percepção dos artistas no que tange às relações contratuais no segmento de HQs, com base na teoria levantada, buscou-se absorver das entrevistas realizadas os seguintes pontos: (a) aspectos próprios de relações contratuais (preço, prazo, etc.); (b) barreiras às relações (assimetria de informações, nobody knows, arte pela arte, entre outras); e (c) proteção dos direitos (propriedade intelectual, direito de comercialização e direito de marca). Todos os aspectos estão analisados sob a ótica do artista.

O instrumento de coleta de dados utilizado foi um roteiro de entrevista informal. Segundo Gil (2007, p. 117), a entrevista é uma "técnica em que o investigador se apresenta frente ao investigado e lhe formula perguntas, com o objetivo de obtenção dos dados que interessam à investigação". Dentre as formas de estruturação 
possível de entrevista, a entrevista informal foi a que melhor se adequou aos propósitos deste estudo, pois ainda conforme este autor (2007, p. 119):

A entrevista informal é recomendada nos estudos exploratórios, que visam abordar realidades pouco conhecidas pelo pesquisador, ou então oferecer visão aproximativa do problema pesquisado. Nos estudos desse tipo, com frequência, recorre-se a entrevistas informais com informantes-chaves, que podem ser especialistas no tema em estudo, líderes formais ou informais, personalidades destacadas etc.

O objeto de análise foi os atores do segmento de HQs no Estado do Ceará. Ao todo foram entrevistados 8 (oito) artistas, tendo sido registrados e posteriormente as entrevistas foram transcritas e analisadas diante dos objetivos da pesquisa. Os respondentes foram: 2 (dois) desenhistas freelance, 3 (três) fanzinistas, 1 (um) quadrinista exportador de desenhos e 2 (dois) figurinistas e quadrinistas de jornais de grande circulação. A pesquisa de campo foi realizada entre maio e agosto de 2008. Os dados obtidos foram tratados conforme a técnica de análise de conteúdo, a qual é considerada "uma técnica para o tratamento de dados que visa identificar o que está sendo dito a respeito de determinado tema" (VERGARA, 2006, p. 15).

\section{Apresentação e Discussão dos Resultados}

O segmento de histórias em quadrinhos no Ceará é marcado principalmente por aspectos amadoristas nas relações negociais. Uma considerável parte dos artistas ainda encara o setor como um hobby e não consegue visualizar o potencial econômico das HQs. Este fato gera a falta de profissionalismo do artista e por consequência o impede de intitular-se desenhista de quadrinhos, pois ele acaba por desempenhar outras atividades inerentes à indústria criativa e bem próximas do segmento de HQs. São elas: caricaturas, fanzines, desenhos comerciais, figurinos, charges, entre outras. Esta divisão fica clara nas palavras de um dos quadrinistas de jornal com 10 anos de atuação no mercado ao afirmar que:

[...] primeiro você tem que definir o que você vende. Existe uma diferença entre desenhista, ilustrador, quadrinista, chargista e cartunista. $\mathrm{O}$ pessoal as vezes mistura estas nomenclaturas e envolve tudo em um bolo só. Na verdade, a primeira coisa é você definir o que é, qual vai ser sua linha de atuação. Nada impede que você atue em vária áreas, nessas cinco áreas ou se especializar em só uma.

No que concerne aos aspectos contratuais, buscou-se saber dos artistas quais são as principais cláusulas e como se dão as negociações. A priori, identificou-se que a maioria das negociações ocorre simplesmente com base em acordos verbais. De regra, segundo a maior parte dos entrevistados, não há um instrumento contratual propriamente dito para a formalização de um negócio. Conforme afirma um dos desenhistas freelance, "Como é que funciona? O cara liga, pede, eu dou meu preço e o cara vai e fecha. Em alguns casos nem por escrito vai o orçamento", ou seja, muitas vezes o processo é dotado de características amadoras desde o início. Porém, um dos artistas que atua em um jornal de grande circulação ressalta que a informalidade é situação de começo de carreira:

Então, a questão da informalidade existe bastante [...] principalmente no começo, quando você está aprendendo, a questão dos fanzines, onde não existe uma preocupação maior de estética e sim de aprendizado; e você começa a absorver o que os mais experientes têm para 
você desenvolver seu trabalho, porque no Brasil ainda são poucas as escolas de ilustração específicas. Tem agora uma em São Paulo uma faculdade que é específica para ilustrador.

Outro artista que trabalha para jornais destaca:

Tem bastante contratações informais [...] Eu acho que as pessoas não dão crédito para a nossa profissão. Então, é muito informal. Aí pelo fato de ser informal todo mundo sabe no que acarreta. Então, você não tem como cobrar e aí te traz muito problema; porque são poucos os profissionais na área, [...] que trabalham a um certo tempo, que têm um knowhow, que conseguem cumprir a suas metas, que entregam os arquivos da maneira correta.

Essa informalidade destacada por ambos os ilustradores que trabalham para jornal fica clarificada com os depoimentos dos três fanzinistas de que as relações são firmadas por meio de acordos verbais, com inexistência de contratos formais, apesar de afirmaram ter registrado alguns de seus personagens. Por outro lado, o artista que trabalha com o mercado internacional ressalta a existência do instrumento contratual em suas negociações. Segundo este, "os contatos são muitas vezes estabelecidos através da internet, por meio dos agentes, ou no contato direto do próprio artista com os produtores das editoras". O mesmo artista que assegura a informalidade em início de carreira destaca que o instrumento contratual faz parte da realidade dos artistas já consolidados. Nas palavras dele:

Com relação aos contratos, as questões inerentes variam muito. Hoje, nós estamos na fase do imediatismo, todo mundo quer para ontem. Tudo depende do trabalho. $\mathrm{O}$ decorrer desse ontem inclui muitas coisas na parte do próprio trabalho. Por quê? Porque existe um trabalho de pesquisa, pesquisa de material e estilo. Então o contrato serve tanto para o ilustrador como para a própria empresa.

Há uma evidente diferenciação na postura da maioria dos artistas que atua no mercado local e daqueles que atuam no mercado internacional ou são contratados de uma instituição, como é o caso dos desenhistas que trabalham para os jornais cearenses. $O$ profissionalismo parece estar mais inerente a estes do que àqueles. Um outro quadrinista que trabalha para um jornal de grande circulação assegura que os contratos seguem as regras gerais, mas que eles enfrentam dificuldades com os contratos de adesão:

Os contratos seguem todo esse cronograma já conhecidos, sendo que a gente ainda tem alguns entraves que são os contratos fabricados. Na realidade, a gente já recebe os contratos feitos do contratante. Não chegam a ser tantos, mas chegam a se assemelhar a quantidade de contratos que nós damos as nossas normas. A maioria das editoras de fora esse contrato já vem estabelecido. Então, você tem que fazer a opção de sim ou não e vender a sua alma e topar ou não o trabalho.

Segundo os artistas que convivem com contratações formais, os instrumentos contratuais são compostos basicamente por cláusulas comuns a todos os contratos. Um deles destaca que:

Não existe uma regra para os contratos. Existem as bases formais de todo contrato: o contratado e o contratante, o que fica estabelecido, as normas de um de outro, o objeto do contrato. Isto é igual a todos as cláusulas. Existe também a questão da refação. [...] Questão de pagamento também: $50 \%$ antes do trabalho e $50 \%$ depois que o projeto é finalizado ou se não for finalizado [...] Então o contrato estabelece o prazo de entrega, estabelece o que 
vai ser e o que está sendo entregue, em que formato vai ser entregue isso, forma de pagamento, quanto tempo de licenciatura e onde vai seu usado esse material [...] E a forma de pagamento. Basicamente é isso.

Ele ainda completa afirmando que o problema é um pouco cultural e localizado. "O que está acontecendo agora aqui em Fortaleza, porque aqui ainda não tem uma cultura, o pessoal aqui fica desconfiado quando se coloca contrato no meio; mas é uma realidade com todo profissional e com toda empresa". Todos esses aspectos caracterizam-se como custos de contrato ex ante.

No que concerne à formação do preço, há diferenças entre os campos de atuação de cada artista. Dependo do tempo de mercado e forma de contratação do artista o "preço pode ser definido por projeto, por uma arte em si ou até mesmo através da contratação do artista como funcionário", é o que afirma um dos desenhistas freelancer com mais de 10 anos de mercado. Por outro lado, os três fanzinistas ressaltam que não há como eles definirem um preço pela arte em si, porque sai muito "caro" e não há como passar esse custo ao consumidor. Para o artista que trabalha ao mercado internacional, o preço é definido por página produzida do quadrinista e fica fixado no ato de assinatura do contrato. Um dos artistas que atua nos jornais destaca os aspectos que são relevantes na composição do preço, ou seja, o preço final do produto firmado em contrato vai depender de três aspectos: como vai ser licenciado, o nível de dificuldade e o tempo para confecção da arte.

Tudo depende de como vai ser usado. [...] tudo isso é pensado na hora da contratação. O valor do desenho, o valor da ilustração, basicamente é como vai ser usado. [...] Então, o valor do desenho é relacionado com... Primeiro é como vai ser licenciado, como é que vai ser usado? É para internet? É para gráficos? Por quanto tempo? Segundo é o nível de dificuldade. É realista? É mais linear? É mais solta? E terceiro por tempo. Por exemplo, se você quer uma ilustração para eu te entregar em uma hora ela vai ser dez mil vezes mais cara do que uma ilustração que eu vou ter que te entregar em uma semana. [...]. Agora, isso não existe uma fórmula. Varia muito de cada profissional, mas basicamente como é que vai ser usado o material.

Em relação às barreiras contratuais, houve uma sintonia entre os aspectos destacados na literatura assimetria de informação, humdrum inputs e arte pela arte - (CAVES, 2003; MCGUIGAN; MOYER; HARRIS, 2004) e as informações coletadas dos artistas. Dentre esses aspectos, a assimetria de informação destaca-se como o maior entrave à profissionalização e ao estabelecimento de relações contratuais. Verificase que tanto artistas como contratantes são vítimas desta barreira às relações. Isso pode ser verificado nas palavras de um dos quadrinistas que trabalha para um jornal:

Há bastante carência de informação [...] Lançaram pela internet um manual do ilustrador [...] Um livro de ética de como cobrar e como se portar com os clientes. E quem leu esse manual viu que todo mundo tem umas dúvidas básicas que não deveria ter sobre as formas de contrato, sobre direitos autorais, sobre propriedade intelectual [...] depois desse manual uma porção de coisas se esclareceram, mas mesmo assim ainda há uma porção de dúvidas. Mas essas dúvidas, com esse manual, irão amenizar; mas como a propriedade intelectual é uma coisa abrangente e como é uma coisa que você tem que estudar muito sobre isso e a maioria dos ilustradores não tem um sindicato, principalmente no nordeste, no Ceará.

Há carência de informações nos contratos principalmente no que diz respeito aos números do setor, quantidade de dinheiro que movimenta e volume de consumidores, há o desconhecimento dos contratantes 
em relação ao trabalho do artista em si, técnicas usadas, tempo gasto, produção intelectual envolvida e por fim há uma dificuldade do desconhecimento dos produtos em si, quais são os produtos, quais os públicos que atingem, etc. Um dos desenhistas freelancer exemplificou:

O contratante quer o que vai fazer sucesso, o que faz sucesso é mangá, eu sou desinformado, então eu quero que você faça um mangá. Cabe ao profissional da área fazer uma assessoria [...] Dizer assim: olha, tu ta criando um produto que não vai ter impacto [...] e se a gente criasse um personagem mesmo? Se a gente pegasse um desenhista que tivesse um estilo mais próprio e criasse um personagem? Aí teria que se valer da aposta [...] aí ele já não tem referências pra isso [...] ele nunca viu nada similar [...] então ele fica muito naquela de que não quer apostar nisso não.

A figura do Humdrum destacada por Caves (2003) não está tão presente no mercado regional de quadrinhos. A ausência deste agente acaba por ser uma barreira ao desenvolvimento do mercado de HQs. Um outro artista freelancer afirma que "a promoção do artista é feita por ele próprio, não havendo agentes intermediando as relações comerciais", confirmando a posição do artista freelancer citado anteriormente no que concerne a esse aspecto:

Não existem pessoas que vejam os quadrinhos como produto realmente. As relações se dão diretamente do produtor com os eventuais clientes do produto final. Há a dificuldade da enorme desvalorização da criação intelectual, principalmente artística. Os clientes querem pagar muito pouco, pois não entendem o processo de criação intelectual e artística.

Essa ausência desse agente não é uma prerrogativa dos artistas freelancer. Nesta mesma linha, um dos desenhistas que atuam para os jornais destaca a inexistência de um agente que vai além das funções premissas de um humdrum, o que reflete a ausência de outros atores da cadeia produtiva do negócio.

A gente é que lida com todo esse tipo de coisa: nota, papel; [...] a gente se perde no meio da produção, porque tem trabalhos que é mais trabalhoso você tirar uma nota. Você calcular, tirar orçamento, entrar em contato, entrar em contato com editor, fazer correção de briefing. Então, você perde muito tempo com isso, entendeu?

Dentre as barreiras à contratação do artista ainda se destaca o sentimento do próprio artista de produzir seus trabalhos por amor a arte. Em relação a isso, não há um consenso entre os quadrinistas, pois aqueles consolidados no mercado, como é o caso dos que trabalham para jornal e para o mercado internacional, afirmam que Art for Art sakes (CAVES, 2003) é um "devaneio" para início de carreira. Isso é verificado nas palavras de um dos quadrinistas de jornal.

Acho que não dá mais para pensar só na arte em si. A não ser que você seja totalmente amador, arranje uma profissão e vá fazer quadrinhos e ilustração para você. Porque o quadrinho [...] precisa de um custo para se comercializar, entendeu? Tem que passar por um editor, uma editora [...] A arte pela arte é você fazer os seus quadrinhos, ter o prazer de desenhar, fazer bem feito, com carinho, com histórias bacanas, publicá-las no mural da sua casa. Mas se você quiser que muitas pessoas leiam os quadrinhos no país todo, você infelizmente tem que entrar no mercado. 
Sobre a questão da proteção dos direitos do artista, isso parece muito claro para todos os entrevistados; entretanto, não há uma preocupação de todos em preservá-los. Alguns entendem que tem direitos sobre a sua obra e que neles se assegura a sua capacidade de contratação. Os direitos envolvidos nas transações das HQs podem ser visualizados nas palavras de um dos quadrinistas de jornal.

Se formos falar em direito, existem os direitos intelectuais, esses não tem como mexer. Você produziu então você é o dono da obra. Direitos intelectuais, direitos morais e... Você na verdade licencia o produto. A gente vende um desenho, a gente não está dando o desenho. Os direitos intelectuais continuam do autor. Agora, eu licencio esse material, né? Esse tempo de licenciamento tem um prazo. Você não pode vender um desenho para sempre.

O outro desenhista que atua junto a jornais de grande circulação dá destaque à importância de saber reconhecer seus direitos a fim de preservar a sua obra.

Alguns ilustradores não ligavam muito para isso e com o tempo você vai vendo o quanto é importante você cuidar da sua obra pro resto da sua vida, porque é sua obra, entendeu? [...] A gente tem que sempre que for fazer contrato lembrar da propriedade de veiculação dos seus produtos, porque até hoje tem produtos sendo comercializados e veiculador que o ilustrador, o dono da obra, não recebe mais nada.

Por fim, cabe destacar a segurança da proteção dos direitos com base na legislação ressaltada por um dos entrevistados que atuam em jornal.

A lei funciona aqui no Brasil. Uma coisa que você deve fazer é que tudo que você produz, você deve guardar o processo. Ter os e-mails, as trocas de e-mails desde as conversas mesmo. Ter os rascunhos. Os primeiros desenhos. [...] No meu caso eu pego tudo, foi até uma orientação do guia do ilustrador, mando tudo pelo correio para minha casa em envelope fechado e aí eu tenho uma prova documentada, carimbada de que aquilo foi produzido naquela época e que aquilo é meu. Então, se chega outro ilustrador dizendo que o trabalho é dele, ele vai ter que provar.

No geral, há uma desinformação acentuada e desconhecimento dos direitos autorais, dos direitos de comercialização e reprodução de marcas ou imagens. É necessária também uma maior organização e profissionalismo dos artistas para a captação de recursos públicos e de empresas que estão disponíveis para financiamento de atividades artísticas. Falta, inclusive, a mentalidade de pensar em toda a cadeia de consumo. A produção de quadrinhos gerar também filmes, roupas, produtos licenciados, música, games, etc.

\section{Conclusões}

Este estudo teve como principal objetivo analisar os aspectos econômicos da relação de artistas, seus contratantes e agentes comerciais da cadeia produtiva das indústrias em quadrinhos, como caso ilustrativo das dificuldades da negociação das indústrias criativas. Os resultados obtidos basearam-se na percepção dos artistas a respeito, principalmente, dos custos de transação, direitos autorais, assimetria de informações e agentes de mercado. 
Da discussão dos resultados, verificou-se a falta de profissionalismo existente no setor de quadrinhos da indústria criativa cearense. Isto pode ser inferido pela observação nas falas dos respondentes, da falta de visão mercadológica e de mentalidade profissional dos artistas, da quase completa ausência de agentes especializados para intermediar comercialmente a relação entre artistas e contratantes, ou entre a arte e o mercado, além da inexistência de proteção aos direitos autorais e conexos nas relações existentes no mercado.

Esses resultados indicam a ausência quase completa de condições institucionais adequadas nesse mercado, que atuem para minimizar fatores causadores de imperfeições, como a assimetria de informações, ou a informação incompleta, chamada por Caves (2003) de nobody knows, o que resulta em incerteza e custos de transação elevados.

A consequência disso é o impedimento do desenvolvimento desse mercado, com prejuízos para objetivos importantes como a utilização do potencial criativo dos artistas locais e a transformação dessa atividade em atividade negociante, com dedicação de artistas e sua transformação em profissionais do ramo.

Espera-se que os resultados apresentados neste estudo possam servir para a melhor compreensão da indústria criativa de quadrinhos, para a melhoria da negociação dos artistas, e para a formulação e a prática de políticas públicas que contribuam para a formação da mentalidade empreendedora, que supra a lacuna de informações sobre as condições do mercado e que apóie a proteção da propriedade intelectual e a melhoria dos termos dos contratos, reduzindo por esses meios a incerteza, os custos de transação e os impedimentos ao desenvolvimento dessas atividades.

É importante ainda reconhecer as limitações desta pesquisa, e por tanto dos resultados aqui debatidos. O principal dos limites diz respeito ao tamanho da amostra, já que esta se restringiu aos principais quadrinistas atuantes no mercado da indústria criativa do Ceará. Portanto, sugere-se que estudos futuros possam ser realizados em outros estados do Brasil. Com isso, haverá também a possibilidade de análises comparativas que revelem as possíveis tendências de percepção dos aspectos aqui abordados, por parte dos artistas brasileiros.

Sugere-se também que novas pesquisas sobre o tema tenha como unidade de investigação outros atores envolvidos no processo, como agentes, empresários, investidores, galerias e editoras, visando obter uma percepção mais abrangente das relações envolvidas. Outros contextos e enfoques também são necessários para uma melhor compreensão de um tema tão abrangente, tais como a análise mercadológica dos impactos dessa atividade no Brasil, além da percepção que os consumidores têm da mesma.

\section{Referências}

ANSELMO, Z. A. História em quadrinhos. Petrópolis: Vozes, 1975.

ARGYRES, N.; ZENGER, T. Are capability-based theories of firm boundaries really distinct from transaction cost theory? Academy of Management Best Paper Proceedings, 2007.

AZEVEDO, P. F. Organização Industrial. In: PINHO, D. B.; VASCONCELlOS, M. A. S. (Orgs.). Manual de Economia: equipe de professores da USP. $5^{\text {a }}$ edição. São Paulo: Saraiva, 2006.

BATISTA, P. C. S; OLIVEIRA, L. G. L; ANDRADE, R. J. C. A propriedade intelectual na indústria de quadrinhos do Ceará. BASE - Revista de Administração e Contabilidade da Unisinos, v. 7, n. 1, p. 14-24, jan.-mar. 2010. 
;________ OLIVEIRA, D. M.; QUEIROZ, F. L. Uma análise da cadeia produtiva do segmento de histórias em quadrinhos na indústria criativa cearense. In: Encontro Nacional da Anpad, 32., 2008 , Rio de Janeiro. Anais... Rio de Janeiro: Anpad, 2008.

BRASIL. Lei n. ${ }^{\circ}$ 9.610, de 19 de fevereiro de 1998. Altera, atualiza e consolida a legislação sobre direitos autorais e dá outras providências. Diário Oficial da União, Brasília, DF, 20 de fevereiro de 1998. Disponível em: <http://www.planalto.gov.br/CCIVIL/Leis/L9610.htm>. Acesso em: 17 de abril de 2008.

CAVEDON, N. R.; LENGLER, J. F. B. Desconstruindo temas e estratégias da administração moderna: uma leitura pósmoderna do mundo de Dilbert. Organizações \& Sociedade, v.12, n.32, p.105-119, jan.-mar. 2005.

CAVES, R. E. Contracts Between Arts and Commerce. Journal of Economics Perspective, v. 17, n. 2, p. 73-83, spring 2003.

CIRNE, M. A linguagem dos quadrinhos: o universo estrutural de Ziraldo e Maurício de Sousa. Petrópolis: Vozes, 1971.

. A explosão criativa dos quadrinhos. 4. ed. Petrópolis: Vozes, 1974.

COASE, R. The Nature of the Firm. Economica, v. 4, n. 16, pp. 386-405, 1937.

EISNER, W. Comics \& sequential art. California: Impact Publishers, 1985.

FAGUNDES, J. Economia institucional: custos de transação e impactos sobre política de defesa da concorrência. Texto para Discussão, $\quad$ n. 407, $1997 . \quad$ Disponível em: <http://www.ie.ufrj.br/grc/pdfs/custos_de_transacao_e_impactos_sobre_politica_de_defesa_da_concorrencia.pdf >. Acesso em: 6 de maio de 2008.

FURLAN, C. HQ e os “syndicates” norte-americanos. In: LUYTEN, S. M. B. (org.). História em quadrinhos: leitura crítica. 2. ed. São Paulo: Paulinas, 1985.

GIL, A. C. Métodos e técnicas de pesquisa social. 5. ed. São Paulo: Atlas, 2007.

GONÇALO JÚNIOR. A guerra dos gibis: a formação do mercado editorial brasileiro e a censura aos quadrinhos, 1933-64. São Paulo: Companhia das letras, 2004.

GRAVETT, P. Mangá: como o Japão reinventou os quadrinhos. São Paulo: Conrad Editora, 2006.

HANSON, D.; GOMES, M. H. T. S. Indústrias criativas e sua relação com a propriedade intelectual. In: Simpósio de Excelência em Gestão e Tecnologia, 4., 2007, Resende. Anais do IV SEGeT, Resende: AEDB, 2007.

HARTLEY, J. Creative Industries. London: Blackwell, 2005.

HENFIL. Diário de um cucaracha. 4. ed. Rio de Janeiro: Record, 1983.

IMF - INTERNATIONAL MONETARY FUND. World Economic Outlook: april, 2008. Disponível em: <http://www.imf.org/external/datamapper/index.php>. Acessado em: 28 de maio de 2008.

LACHTERMACHER, S.; MIGUEL, E. HQ no Brasil: sua história e luta pelo mercado. In: LUYTEN, S. M. B. (org.). História em quadrinhos: leitura crítica. 2. ed. São Paulo: Paulinas, 1985.

MAGALHÃES, H. O bom humor das tiras brasileiras. In. GUIMARÃES, E. (org.). O que história em quadrinhos brasileira. João Pessoa: Marca de Fantasia, 2005.

MARTINS FILHO, P. Direitos autorais na Internet. Ciência da Informação, v. 27, n. 2. Brasília: Ibict, maio/ago, 1998. pp. 183-188. Disponível em: <http://revista.ibict.br/index.php/ciinf/article/view/362/323>. Acesso em: 16 de maio de 2008.

MCCLOUD, S. Desvendando os quadrinhos. São Paulo: Makron Books, 1995. 
McGUigAn, J. R.; MOYER, R. C.; HARRIS, F. H. B. Economia de Empresas: aplicações, estratégia e táticas. Tradução: Roberto Galman. São Paulo: Pioneira Thomson Learning, 2004.

MOREIRA, C. F. M. A natureza jurídica dos personagens de histórias em quadrinhos que se tornam símbolo identificador de um produto comercial. Direito UNIFACS, v. 1, n. 6, nov. 2000. Disponível em: <http://web.unifacs.br/revistajuridica/edicao_novembro2000/corpodiscente/graduacao/natureza_juridica_personagens.ht m>. Acesso em: 10 de maio de 2008 .

MOYA, Á. de. Shazam! 3. ed. São Paulo: Perspectiva, 1977.

PATATI, C.; BRAGA, F. Almanaque dos quadrinhos: 100 anos de uma mídia popular. Rio de Janeiro: Ediouro, 2006.

PEREIRA, J. M. Política de proteção à propriedade intelectual no Brasil. In: Encontro Nacional da Anpad, 27., 2003, Rio de Janeiro. Anais... Rio de Janeiro: Anpad, 2003.

PESSALI, H. F. Teoria dos Custos de Transação: uma avaliação à luz de diferentes correntes do pensamento econômico. Dissertação de Mestrado. 155 p. SCSA/UFPR. Curitiba, 1998.

RICHARDSON, R. J. Pesquisa social: métodos e técnicas. 3. ed. São Paulo: Atlas, 1999.

SANTANA, E. A. Estratégia de geração ao mínimo custo e assimetria de informações: o caso da operação do mercado de energia elétrica do Brasil. In: Encontro Nacional de Economia, 32., 2004, João Pessoa. Anais eletrônicos... João Pessoa: Anpec, 2004. Disponível em: 〈http://www.anpec.org.br/encontro2004/artigos/A04A088.pdf>. Acesso em: 15 de maio de 2008 .

SANTANA, E. A. Economia dos custos de transação, direito de propriedade e a conduta das empresas no setor elétrico brasileiro. In: Encontro Nacional de Economia, 34., 2006, Salvador. Anais eletrônicos... Salvador: Anpec, 2006. Disponível em: <http://www.anpec.org.br/encontro2006/artigos/ A06A065.pdf>. Acesso em: 10 de maio de 2008.

SECULT/CE - SECRETARIA DE CULTURA DO ESTADO DO CEARÁ. Revela Ceará Jovem. Disponível em: <http://www.secult.ce.gov.br/>. Acessado em 29 de outubro de 2008.

UN - UNITED NATIONS -. Creative Economy Report 2008. The Challenge of Assessing the Creative Economy: towards informed policy-making. Disponível em: <http://www.unctad.org/en/docs//ditc20082cer_en.pdf>. Acesso em: 28 de maio de 2008 .

VERGARA, S. C. Métodos de pesquisa em administração. 2. ed. São Paulo: Atlas, 2006.

VERGUEIRO, W. La actualidad de los cómics en Brasil: la búsqueda de un nuevo público. In: Congress of the Latin American Studies Association, 2007, Montreal. Anais... Montreal: Congress of the Latin American Studies Association, 2007.

; SANTOS, R. E. A pesquisa sobre histórias em quadrinhos na Universidade de São Paulo: análise da produção de 1972 a 2005. UNIrevista, São Leopoldo, v.1, n.3, p.1-12, jul, 2006.

VIEIRA, M. M. F.; ZOUAIN, D. M (Orgs.). Pesquisa qualitativa em administração: teoria e prática. 2. ed. Rio de Janeiro: Editora FGV, 2005.

WILLIAMSON, O. E. The economic institutions of capitalism: firms, markets, relational contracting. New York: The Free Press, 1985.

WIPO - WORLD INTELLECTUAL PROPERTY ORGANIZATION. Berne convention for the protection of literary and artistic works. Geneva: WIPO Publication, 28 sep. 1979.

Curso Geral da Propriedade Intelectual. Material de Didático do Programa de Ensino à Distância. Academia Mundial da WIPO, 2004. 